\title{
Open transcatheter mitral valve replacement for severe mitral annular calcification: An ideal hybrid?
}

\author{
Michael A. Borger, MD, PhD, and David M. Holzhey, MD, PhD
}

\footnotetext{
From the Department of Cardiac Surgery, Leipzig Heart Center, University Clinic of Cardiac Surgery, Leipzig, Germany.

Disclosures: Dr Borger receives speakers honoraria and consulting fees from Edwards Lifesciences, Medtronic, Abbott, and CryoLife. Dr Holzhey has served as a proctor for Boston Scientific, as a proctor for SJM, and as an advisor for Medtronic.

Received for publication Nov 27, 2018; accepted for publication Nov 28, 2018; available ahead of print Jan 9, 2019.

Address for reprints: Michael A. Borger, MD, PhD, Department of Cardiac Surgery, Leipzig Heart Center, University Clinic of Cardiac Surgery, Struempellstrasse 39, 04289 Leipzig, Germany (E-mail: michael.borger@ helios-kliniken.de).

J Thorac Cardiovasc Surg 2019;157:917-8

$0022-5223 / \$ 36.00$

Copyright (C) 2018 by The American Association for Thoracic Surgery

https://doi.org/10.1016/j.jtcvs.2018.11.126
}

Mitral annular calcification (MAC) is among the most challenging problems in cardiac surgery. In addition to the technical challenges associated with conventional surgical management, severe MAC often presents in elderly patients with a high risk profile. Although conventional surgery can be performed with good results in patients with isolated mitral valve (MV) disease and less-severe forms of MAC, patients with circumferential severe MAC frequently require concomitant procedures and have worse survival.

Given the marked technical challenges and variety of severe complications that can occur with conventional surgical approaches to severe MAC, an attempt to address this problem with transcatheter techniques (ie, transfemoral or transapical) was justified. But for several reasons-left ventricular outflow tract obstruction and insecure anchoring of the transcatheter valve, in particular-this technique is associated with increased periprocedural mortality and remains restricted to select patients. ${ }^{2,3}$

An alternative hybrid approach to severe MAC; that is, open transatrial implantation of balloon-expandable valves, was initially described in case reports as either a planned procedure or as an intraoperative bailout maneuver. ${ }^{4,5}$ In 2018, Praz and colleagues ${ }^{6}$ published a multicenter experience of 26 such patients that included concomitant cardiac procedures (mostly aortic valve replacement) in more than one-half. The abovementioned work demonstrated that this novel hybrid technique is feasible and hemodynamically effective, with low transmitral gradients and trace or mild mitral regurgitation achieved in nearly all patients. However, the perioperative mortality for this procedure remained substantial. Part of the elevated mortality was related to the fact that this is an elderly patient population with a high risk profile, but part was also related to the learning curve that is associated with any new technique. Personal communication with our

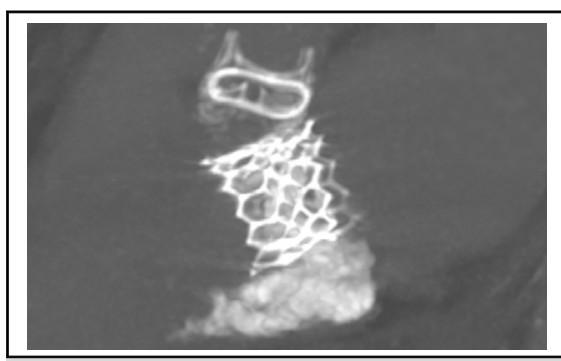

Postoperative computed tomography image of a patient who underwent combined aortic valve replacement and transatrial balloon-expandable mitral valve replacement in severe mitral annular calcification.

\section{Central Message}

Mitral annular calcification (MAC) is a challenging problem. A step-by-step description of transatrial mitral valve replacement with a balloon-expandable valve is described for MAC.

See Article page 907. colleagues at several cardiac centers has revealed that many are turning to this novel solution for severe MAC. It is therefore high time for a structured step-by-step description of this technique.

Russell and colleagues ${ }^{7}$ provide a detailed description of hybrid transatrial MV replacement using a balloonexpandable valve that is likely to serve as a roadmap for surgeons and cardiologists treating these challenging patients. Using their systematic approach, the investigators achieved $0 \%$ mortality in a single-center experience of 8 patients undergoing MV replacement with or without tricuspid valve repair.

The detailed description of preoperative computed tomography measurements will be particularly helpful for surgeons who are not familiar with these techniques. Although thorough preoperative planning is essential, we find that left ventricular outflow tract obstruction is very unusual once the anterior leaflet is completely excised. Also, it is our experience that sizing can be done intraoperatively with metric sizing templates (eg, Epic valve sizers [Abbott-St Jude Medical, Minneapolis, Minn]). If the annulus turns out to be too large for the available transcatheter valve, the insertion of commissural sutures with large felt pledgets results in sufficient size reduction. 
The value of the review article by Russell and colleagues $^{7}$ is not only in the comprehensive procedural description, including potential variations, but also in the proof that even high-risk patients with technically challenging pathology can be successfully treated. From our own series, we believe that transatrial delivery of a balloon-expandable prosthesis in the mitral position can be performed safely with hemodynamic results that are just as good, if not better, than traditional biological valve prosthesis replacement. If the currently unknown longterm data for this technique is as promising as the shortterm results, this novel hybrid procedure might replace other solutions to severe MAC such as patch reconstruction of the posterior annulus.

As we continue to explore the rapidly evolving era of transcatheter valve therapy, hybrid solutions may pose an optimal solution to patients with anatomically challenging disease processes.

\section{References}

1. Saran N, Greason KL, Schaff HV, Cicek SM, Daly RC, Maltais S, et al. Does mitral valve calcium in patients undergoing mitral valve replacement portend worse survival? Ann Thorac Surg. November 1, 2018 [Epub ahead of print].

2. Kiefer P, Noack T, Seeburger J, Hoyer A, Linke A, Mangner N, et al. Transapical mitral valve implantation for native mitral valve stenosis using a balloonexpandable prosthesis. Ann Thorac Surg. 2017;104:2030-6.

3. Guerrero M, Urena M, Himbert D, Wang DD, Eleid M, Kodali S, et al. 1-year outcomes of transcatheter mitral valve replacement in patients with severe mitral annular calcification. J Am Coll Cardiol. 2018;71:1841-53.

4. Lee R, Fukuhara S, George I, Borger MA. Mitral valve replacement with a transcatheter valve in the setting of severe mitral annular calcification. J Thorac Cardiovasc Surg. 2016;151:e47-9.

5. Carrel TWP, Reineke S, Simon R, Eberle B, Windecker S, Huber C. Worldwide first surgical implantation of a transcatheter valved stent in mitral position. Cardiovasc Med. 2012;15:202-5.

6. Praz F, Khalique OK, Lee R, Veeragandham R, Russell H, Guerrero M, et al. Transatrial implantation of a transcatheter heart valve for severe mitral annular calcification. J Thorac Cardiovasc Surg. 2018;156:132-42.

7. Russell HM, Guerrero ME, Salinger MH, Manzuk MA, Pursnani AK, Wang D, et al. Open atrial transcatheter mitral valve replacement in patients with mitral annular calcification. J Thorac Cardiovasc Surg. 2019;157:907-16. 